Research Article

\title{
The Permitted Dimension of Guide Sign in Freeway Tunnel Restricted by the Geometric Space of the Tunnel Vault
}

\author{
Jiangbi Hu $(\mathbb{D}$, Lucheng He, Ronghua Wang $(\mathbb{D}$, Chike Yuan $(\mathbb{D}$, and Xiaojuan Gao \\ College of Architecture and Civil Engineering, Beijing University of Technology, Beijing 100124, China \\ Correspondence should be addressed to Ronghua Wang; wangrh@bjut.edu.cn
}

Received 17 April 2020; Accepted 25 June 2020; Published 27 July 2020

Academic Editor: Michele Guida

Copyright (c) 2020 Jiangbi Hu et al. This is an open access article distributed under the Creative Commons Attribution License, which permits unrestricted use, distribution, and reproduction in any medium, provided the original work is properly cited.

Traffic guide signs should be settled in a freeway tunnel when there is a short distance between the interchange exit ramp and the tunnel exit in order to provide enough reaction time for drivers. However, there is not enough space for guide sign in a tunnel adopting the same design method as the guide sign along the general segment of the freeway. The maximum dimension of a guide sign in tunnel should be studied firstly. Based on the analysis of the characteristics of the inner outline design of the tunnel and its relationship with the guide sign dimension, the study was classified into different combination conditions: left superelevation and right superelevation under two-, three-, or four-lane freeway tunnels, respectively. The essential elements, the horizontal and vertical clearances, the radius of the tunnel vault circles, the angle of the superelevation, and the allowance vertical dimension for future sign installation were all taken into account to establish the dimension model of the guide sign in the tunnel. The maximum dimensions of the guide signs were proposed under different combination conditions. The results indicated that there is only one set of the width and the height to obtain the maximum area of the guide sign in the freeway tunnel. The height of the guide sign reduces with the increase of its widths, and the area of the guide sign increases and then reduces with the increase of its width under the same grade of superelevation. The changing trend and extent of the dimension of the guide sign under left superelevation condition were different from those under right superelevation.

\section{Introduction}

At the end of 2018, the total mileage of highways in China is 4.8465 million kilometers, and the highway density is $50.48 \mathrm{~km} / 100 \mathrm{~km}^{2}$. The mileage of freeway is up to $142600 \mathrm{~km}[1]$. The highway network is with high density in the central plain region and southeastern developed economic region. In order to improve social sustainability and economic growth especially in the northwestern and southwestern region, highway network is planned to solve the travel problem in the poverty-stricken and backward areas. Limited by topographic conditions, highway tunnels are constructed to connect different destinations. At present, there are more than 17730 highway tunnels, and the mileage of highway tunnels is longer than $17236.1 \mathrm{~km}$ [1]. When two destinations are close and the freeway is designed to approach different directions in mountainous and hilly areas, infrastructures such as interchanges and tunnels are essential to implement these functions.
When the distance between the freeway tunnel exit and the interchange exit ramps is too close to provide drivers enough reaction time, drivers would miss the interchange exit ramps, which would result in dangerous driving behaviors, such as braking abruptly, reversing, and even driving in the opposite direction. At this situation, guide signs should be set up in the tunnel at several stages in order to provide drivers specific road information. Generally, the size of the guide sign is determined by the highway functions, word messages. However, different from the guide sign along the general section of freeway, there is not enough space for guide sign with the same road information in the freeway tunnel section. The dimension of guide sign design along freeway tunnel segment is restricted by the tunnel inner outline, tunnel clearances, and the fan system, which influences the heights, the widths, and the installation location of the guide signs. The size of the guide sign in freeway tunnel is limited, but what the actual maximum size of the guide sign is has to be studied in order to specify the length 
of the message and the size of the lettering necessary for proper legibility.

Some researchers have studied the settings of traffic signs in the freeway tunnel segments. Yan et al. analyzed the effectiveness of traffic signs settings along adjacent tunnels, studied the lateral location, vertical location of traffic signs, and the distance from traffic sign to the tunnel exit, and then proposed the distance calculation model based on the driver's visual inert as well as the rate of change of the pupil area [2]. Pu et al. built test scenarios using DIALux software and conducted field tests to assess the siting and layout of LED traffic guide signs, and they recommended the optimal design for urban tunnels with speed of $60 \mathrm{~km} / \mathrm{h}$ regarding legibility distance [3]. Wu and Dong combined with drivers' psychological and physiological characteristics, based on the concept of the visual continuity of drivers, analyzed and calculated the exact positions of traffic signs along the tunnels' horizontal and vertical curve sections [4]. These studies focused on the location of the traffic signs in freeway tunnels, the relationship between the visual recognition and the recognition distances. A problem would exist that a traffic guide sign can satisfy the visual recognition requirements, but the tunnel clearances cannot accommodate the dimension of the guide signs.

Then tunnel inner outline directly influences the tunnel clearances, vertical and horizontal clearances, which mainly determine the dimension of guide signs in tunnel segment. According to the engineering practice, the highway tunnel inner outline generally adopts three-centered circular arch. The tunnel vault is a semicircle with large central angle, the sidewall of tunnel is an arc with large radius, and the inverted arch and the side-wall are connected by an arc with small radius. This highway tunnel sectional form shows obvious advantages in mechanical characteristics of structures, costefficiency, easy installation of facilities, and so on. Researchers and engineers proposed the calculation methods and formulas of geometric parameters of different highway tunnel inner outline, considering design speeds, clearances under different lane numbers. The values of the key technical parameters of tunnel inner outline were proposed ranging from $60 \mathrm{~km} / \mathrm{h}$ to $120 \mathrm{~km} / \mathrm{h}$, which is broadly applied in the one-way two-lane freeway tunnel [5-9]. The highway tunnels with three and four lanes are rarely constructed at the present stage in China, and the calculation methods of the technical parameters of these kinds of highway tunnels inner outline are still in the early stage [10]. The present design of inner outline is drawn based on the experience of the twolane highway tunnel, and the result should be further verified through engineering practice. Researches about large crosssection of highway tunnels mainly focus on the construction scheme, the law of surrounding rock deformation, and stress variation based on using analog simulations and numerical calculations [11-14]. The maximum dimension of guide sign in highway tunnel with large cross-section is rarely investigated. $\mathrm{Wu}$ and Dong mentioned the inner outline and tunnel clearances in their research, but the specific parameters about inner outline were not taken as limited conditions to determine the maximum dimensions of traffic signs in tunnel [4].
As mentioned earlier, the tunnel inner outline influences the size of the guide sign. Meanwhile, the alignments and the superelevation should also be considered. Based on the analysis of the inner outline design of tunnel and the design indicators of guide sign in tunnel, this paper is going to study the major factors influencing the dimension of guide sign. The relationship between these major factors and the width, the height, and the area of guide sign would be analyzed, in order to establish the relational models for two-lane one-way freeway tunnel, and for three- or four-lane freeway tunnel. Finally, the maximum widths, heights, and the corresponding area would be recommended under different design speeds, different superelevation for two-lane tunnel, three-, and four-lane tunnel. The result would provide a critical guidance for the dimension design of guide sign in tunnels.

\section{Inner Outline Design of Tunnel and Dimension Design of Signs Analysis}

The vertical clearance and horizontal clearance should be designed to provide a safe travel environment and orientation, considering emergency escape, ease of maintenance, and operations. Obstacles in tunnel, including light fixtures, ventilation, signs, signals, and others, should not intrude into tunnel clearance. Other than tunnel structural safety, inner outline design should satisfy the needs of clearance, as well as lanes, shoulders on both sides, and emergency walkways.

A graphical method is used to determine the inner outline of freeway tunnel. Two-lane freeway tunnel is the most common condition. With the development of technologies and transportation needs, a three-lane or four-lane tunnel is being designed and constructed. In order to reduce the amount of excavation, the graphical method of three- or four-lane tunnel is different from the method of two-lane tunnels. As illustrated in Figure 1 and Table 1, the inner outline of two-lane freeway tunnel is composed of IPJ, JL, LQK, and KI. However, IGM and NHJ, the radius of which is different from the radius of tunnel vault, are added to the inner outline. Therefore, the inner outline of three- or fourlane freeway tunnel is composed of MPN, NHJ, JL, LQK, KI, and IGM. The center of a tunnel vault circle $\left(O_{1}\right)$ is the intersection of line EF and centerline $\mathrm{PQ}$ for two-lane tunnel, and the elevation $O_{1}$ in Figure 1(a) is higher than the elevation of tunnel pavement, whereas the elevation $O_{1}$ in Figure 1(b) is lower than the elevation of tunnel pavement.

In order to provide necessary, clear, and accurate road information, guide sign dimensions are the most essential elements to be specified. Along the ordinary section of the freeway corridor, one guide sign dimension could be calculated according to the amount of route information that should be provided to road users. However, due to the limited space between the inner outline and clearances in freeway tunnel, more route and site road information cannot be included in only one guide sign. As a result, the maximum size of the guide sign in freeway tunnel should be known first. 


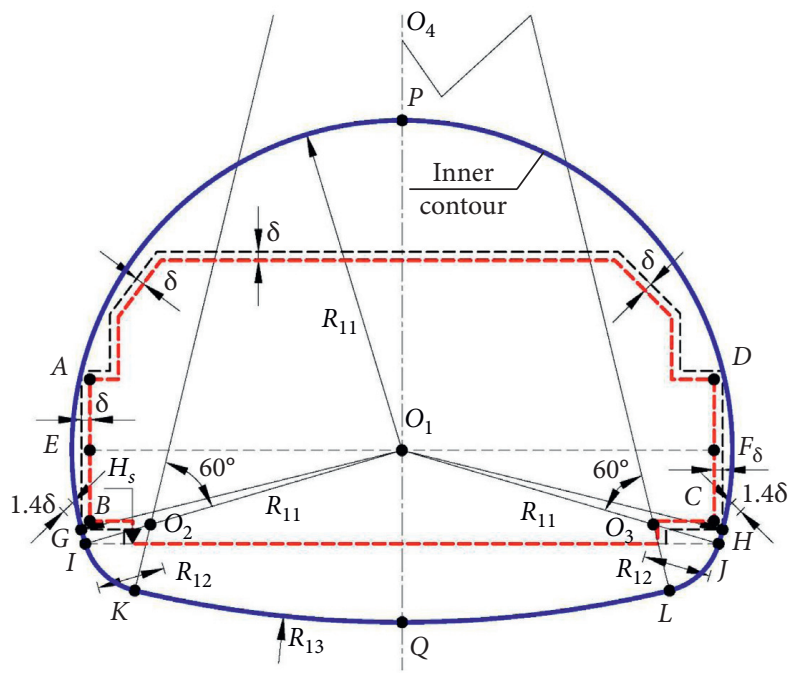

(a)

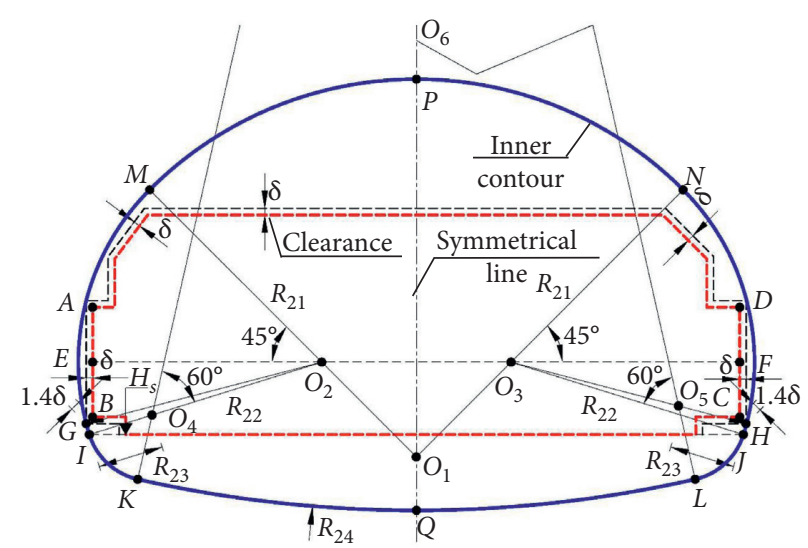

(b)

Figure 1: The inner outline of freeway tunnel. (a) Two-Lane Tunnel. (b) Three- or Four-Lane Tunnel.

TABLE 1: Legends and explanations of the inner outline in Figure 1.

\begin{tabular}{|c|c|c|c|}
\hline Tunnels & Legend & Explanation & Arc radius \\
\hline Two-lane freeway tunnel in Figure 1(a) & $\begin{array}{c}O_{1} \\
\text { IPJ } \\
\text { KI and JL } \\
\text { LQK } \\
\end{array}$ & $\begin{array}{c}\text { Center of a tunnel vault circle } \\
\text { Tunnel vault } \\
\text { Tunnel arch foot } \\
\text { Tunnel inverted arch } \\
\end{array}$ & $\begin{array}{l}\mathrm{IPJ} \longrightarrow R 11 \\
\mathrm{KI} \underset{\mathrm{LQK}}{\longrightarrow} R 12 ; \mathrm{JL} \longrightarrow R 13\end{array}$ \\
\hline Three- or four-lane freeway tunnel in Figure 1(b) & $\begin{array}{c}O_{1} \\
\text { MPN } \\
\text { IGM and NHJ } \\
\text { KI and JL } \\
\text { LQK }\end{array}$ & $\begin{array}{c}\text { Center of a tunnel vault circle } \\
\text { Tunnel vault } \\
\text { Tunnel middle part } \\
\text { Tunnel arch foot } \\
\text { Tunnel inverted arch }\end{array}$ & $\begin{array}{l}\stackrel{\mathrm{MPN} \longrightarrow R 21}{\longrightarrow} \mathrm{MGI} \longrightarrow R 22 ; \mathrm{NHJ} \longrightarrow R 22 \\
\mathrm{KI} \longrightarrow \mathrm{R} 23 ; \mathrm{JL} \longrightarrow R 32 \\
\mathrm{KQL} \longrightarrow R 24\end{array}$ \\
\hline
\end{tabular}

As illustrated above and other than the space between the inner outline and clearances, the maximum dimension of guide sign is also related to the number of lanes, superelevation, vault radius, the center of a tunnel vault circle, and so on. If the superelevation is designed on the horizontal alignment, the horizontal and vertical clearances should be adjusted on the premise of keeping the inner outline unchanged, as shown in Figure 2.

\section{The Dimension of Guide Sign Modelling}

The design elements of the inner outline of two-lane oneway freeway tunnel are different from those of three- and four-lane one-way freeway tunnel. The model of guide sign dimension should be established in two cases.

3.1. The Guide Sign Dimension along Two-Lane One-Way Freeway Tunnel. In the two-lane one-way freeway tunnel condition, the center of the tunnel vault circle is above the tunnel pavement. As shown in Figure 3, the maximum space for the guide sign, rectangle BFGE, is sketched. An allowance altitude $h_{3}$ should be added to the vertical clearance for future sign installation, and the shadow rectangular area is represented as the guide sign. According to the geometric relationship between the center of the tunnel vault circle and the shadow rectangular area, the radius of the tunnel vault circle can be indicated as (1).

$$
R^{2}=W^{2}+\left[\left(H_{t} \cos \alpha-h_{1}\right)+h_{2}+H+h_{3}\right]^{2}
$$

where $R$ is the radius of the tunnel vault circle; $W$ is half of the width of the guide sign. $H$ is the height of the guide sign; $H_{t}$ is the vertical clearance; $\alpha$ is the angle of the superelevation. $h_{0}$ is the height difference between the center of the tunnel vault and designed elevation. $h_{1}$ is the vertical dimension between the center of the tunnel vault and the pavement (including superelevation). $h_{2}$ equals the vertical distance between the middle point of the lower edge of the guide sign and the pavement minus vertical clearance, and $h_{2}=W_{i} . h_{3}$ is the allowance vertical dimension for future installation. $\mathrm{B}$ is the horizontal dimension between the center of the tunnel vault and the datum mark. According to Figure $3, h_{1}=h_{0} \pm B_{i}$, and "+" is for left superelevation and “-” is for right superelevation.

Since the maximum superelevation should be lower than $4 \%$ along the freeway tunnel section, it means that $\tan \alpha=i \epsilon$ $[0,4 \%], \cos \alpha \approx 1$ and $i^{2} \approx 0$. All these parameters are put into equation (1), and Matlab is applied to establish the model of the height, the width, and the area of the guide sign. As 


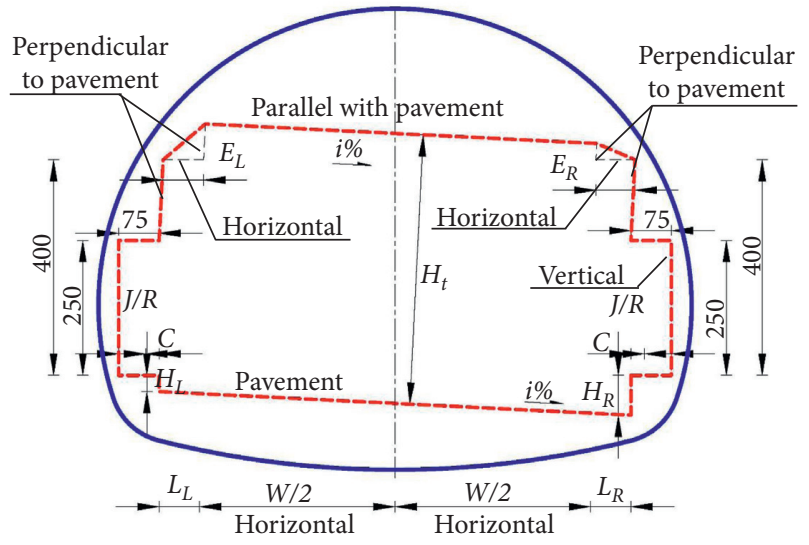

(a)

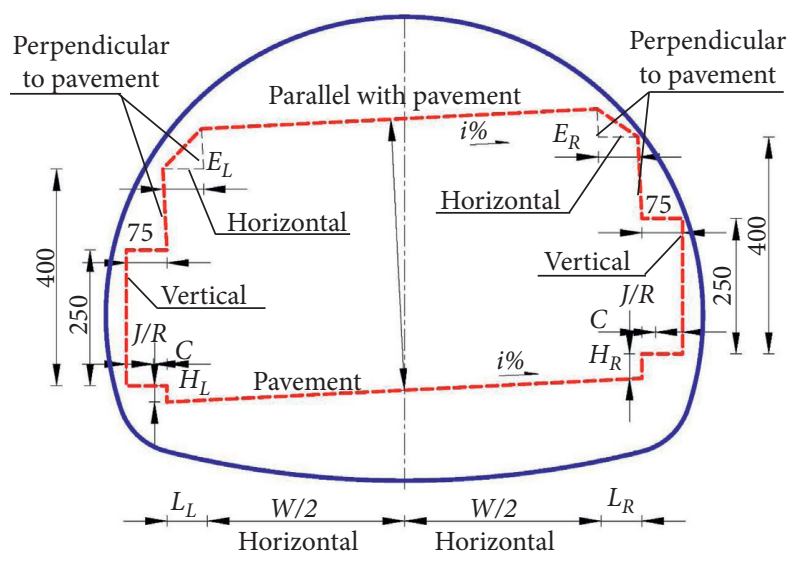

(b)

FIgURE 2: The horizontal and vertical clearances when the superelevation is designed along the horizontal alignment. (a) Left Superelevation. (b) Right Superelevation.

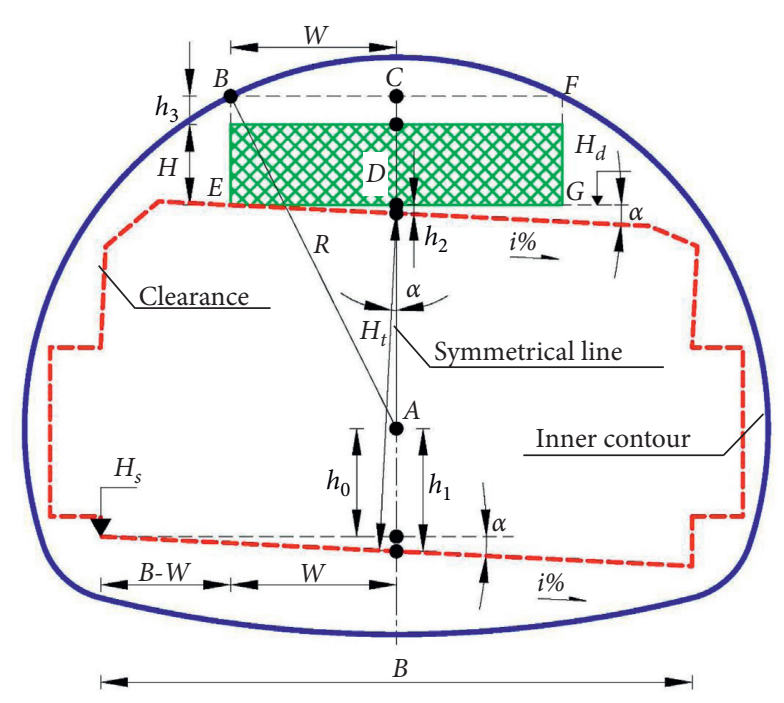

(a)

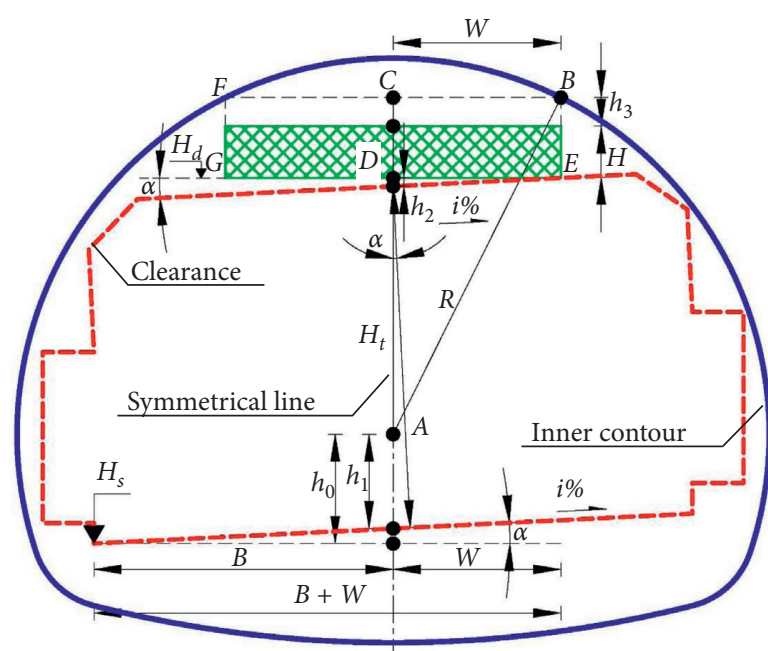

(b)

Figure 3: The guide sign geometric diagram in two-lane one-way freeway tunnel. (a) Left Superelevation. (b) Right Superelevation.

shown in equations (2)-(4), the precise position $E$ in Figure 3 should be determined for guide sign installation. $D_{E}$ and $D_{h}$ should be calculated in order to define the coordinate of point $E$. $D_{E}$ and $D_{h}$ are the horizontal and vertical dimensions, respectively between point $E$ and the datum mark, as shown in equations (5) and (6).

$$
\begin{aligned}
& H=\left\{\begin{array}{l}
H_{(T, \mathrm{LSE})}=\sqrt{R^{2}-W^{2}}+h_{0}-H_{t}-h_{3}+(B-W) i, \\
H_{(T, \mathrm{RSE})}=\sqrt{R^{2}-W^{2}}+h_{0}-H_{t}-h_{3}-(B+W) i,
\end{array}\right. \\
& W=\left\{\begin{array}{l}
W_{(T, \mathrm{LSE})}=\sqrt{R^{2}-\left(H+H_{t}+h_{3}-h_{0}-B i\right)^{2}}-\left(H+H_{t}+h_{3}-h_{0}\right) i, \\
W_{(T, \mathrm{RSE})}=\sqrt{R^{2}-\left(H+H_{t}+h_{3}-h_{0}+B i\right)^{2}}-\left(H+H_{t}+h_{3}-h_{0}\right) i,
\end{array}\right. \\
& A=W \times H=\left\{\begin{array}{l}
A_{(T, \mathrm{LSE})}=W \times\left[\sqrt{R^{2}-W^{2}}+h_{0}-H_{t}-h_{3}+(B-W) i\right], \\
A_{(T, \mathrm{RSE})}=W \times\left[\sqrt{R^{2}-W^{2}}+h_{0}-H_{t}-h_{3}-(B+W) i\right],
\end{array}\right.
\end{aligned}
$$




$$
\begin{aligned}
& D_{E}=\left\{\begin{array}{l}
B-W, \\
B+W,
\end{array}\right. \\
& D_{h}=H_{d}-H_{s}=\left\{\begin{array}{l}
H_{t}-(B-W) i=H_{t}-D_{h} i, \\
H_{t}+(B+W) i=H_{t}+D_{h} i .
\end{array}\right.
\end{aligned}
$$

In the case of two-lane freeway tunnel, $H_{(T, \text { LSE }}$ and $H_{(T}$, ${ }_{\text {RSE) }}$ are the height of the guide sign under left superelevation condition and right superelevation condition, respectively. $W_{(T, \text { LSE })}$ and $W_{(T, R S E)}$ indicate the widths of the guide sign under left and right superelevation conditions, respectively. $A_{(T, \mathrm{LSE})}$ and $A_{(T, \mathrm{RSE})}$ mean the area of the guide sign under left superelevation condition and right superelevation condition, respectively. $H_{s}$ is the design elevation of the datum mark, and $H_{d}$ represents the elevation of the lower edge of the guide sign.

3.2. The Guide Sign Dimension along Three- and Four-Lane One-Way Freeway Tunnel. Unlike the two-lane one-way freeway tunnel condition, the center of the tunnel vault circle is under the tunnel pavement in the three- and four-lane one-way freeway tunnels. The same drawing method is used, and the maximum rectangle BFGE, an allowance altitude $h_{3}$, and the shadow rectangular area of the guide sign are sketched in Figure 4. The radius of the tunnel vault circle can be implied as equation (7). The models of the height, the width, and the area of the guide sign along the three- and four-lane freeway tunnels are established, as shown in equations (2)-(4). In this case, the equations of $D_{E}$ and $D_{h}$ are similar to equations (5) and (6).

$$
\begin{aligned}
& R^{2}=W^{2}+\left[\left(H_{t} \cos \alpha+h_{1}\right)+h_{2}+H+h_{3}\right]^{2}, \\
& H=\left\{\begin{array}{l}
H_{(\mathrm{TF}, \mathrm{LSE})}=\sqrt{R^{2}-W^{2}}-h_{0}-H_{t}-h_{3}+(B-W) i, \\
H_{(\mathrm{TF}, \mathrm{RSE})}=\sqrt{R^{2}-W^{2}}-h_{0}-H_{t}-h_{3}-(B+W) i,
\end{array}\right. \\
& W=\left\{\begin{array}{l}
W_{(\mathrm{TF}, \mathrm{LSE})}=\sqrt{R^{2}-\left(H+H_{t}+h_{3}+h_{0}-B i\right)^{2}}-\left(H+H_{t}+h_{3}+h_{0}\right) i, \\
W_{(\mathrm{TF}, \mathrm{RSE})}=\sqrt{R^{2}-\left(H+H_{t}+h_{3}+h_{0}+B i\right)^{2}}-\left(H+H_{t}+h_{3}+h_{0}\right) i,
\end{array}\right. \\
& A=W \times H=\left\{\begin{array}{l}
A_{(\mathrm{TF}, \mathrm{LSE})}=W \times\left[\sqrt{R^{2}-W^{2}}-h_{0}-H_{t}-h_{3}+(B-W) i\right], \\
A_{(\mathrm{TF}, \mathrm{RSE})}=W \times\left[\sqrt{R^{2}-W^{2}}-h_{0}-H_{t}-h_{3}-(B+W) i\right] .
\end{array}\right.
\end{aligned}
$$

Similarly, $H, W$ and $A$ are represented as the height, the width, and the area of the guide sign. Subscripts (TF, LSE) and (TF, RSE) are for the condition left superelevation and right superelevation along the three- and four-lane freeway tunnels, respectively.

\section{Results and Analysis}

\subsection{The Size of the Guide Sign in the Freeway Tunnel}

4.1.1. Parameter Values in the Models. In order to calculate the guide sign size, all parameter values in the dimension model should be decided firstly. According to the Specifications for Design of Highway Tunnels [15] and Technical Standard of Highway Engineering [16], parameter values for two-lane freeway tunnel could be collected as shown in Table 2. Three- and four-lane freeway tunnels are rarely constructed in China, and there is no standard. According to engineering case, such as Yuehuan Tunnel of GuangzhouZhuhai freeway (three-lane) in Guangdong Province and Jiangshuiquan Tunnel of Jinan 2th ring freeway in Shandong Province (four-lane) in China, parameter values in the dimension model for three- and four-lane freeway tunnels were collected as shown in Table 2.

4.1.2. The Calculation Results of the Guide Sign. In order to determine the maximum area of the guide sign, $\mathrm{d} A / \mathrm{d} W=0$ and the relationship between all parameters, the widths, and heights of guide signs is shown in equation (11). 


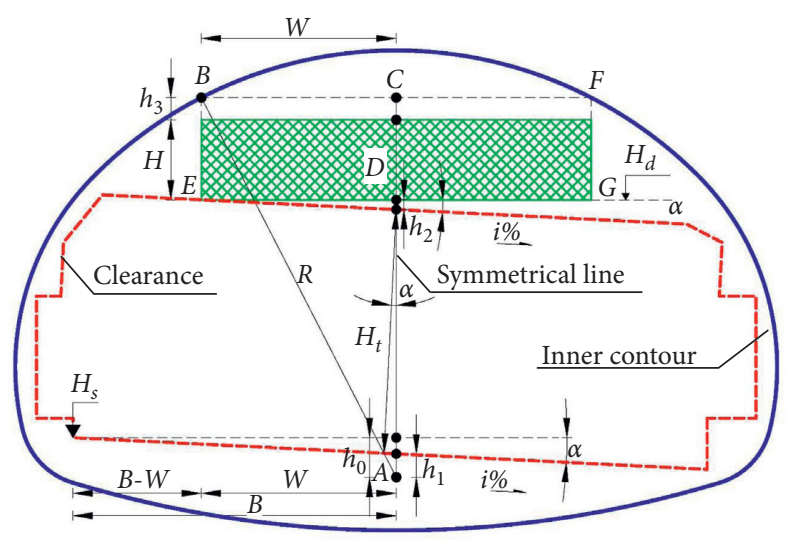

(a)

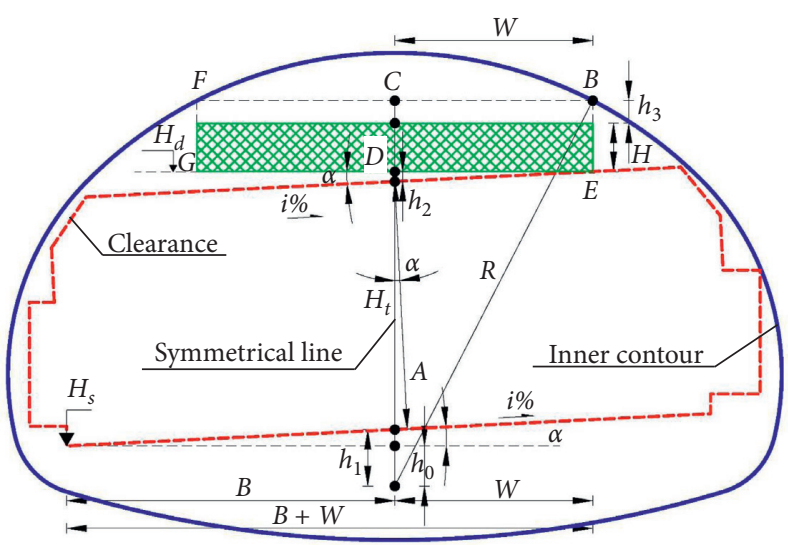

(b)

Figure 4: The guide sign geometric diagram in three-and four-lane one-way freeway tunnels. (a) Left Superelevation. (b) Right Superelevation.

TABle 2: Parameter values for the guide sign dimension model.

\begin{tabular}{lcccccccc}
\hline \multicolumn{2}{l}{ Two-lane one-way tunnel } & \multicolumn{4}{c}{ Three-and four-lane one-way tunnel } \\
$R(\mathrm{~m})$ & $h_{0}(\mathrm{~cm})$ & $B(\mathrm{~cm})$ & $h_{3}(\mathrm{~cm})$ & $H_{t}(\mathrm{~cm})$ & $R(\mathrm{~m})$ & $h_{0}(\mathrm{~cm})$ & $B(\mathrm{~cm})$ & $h_{3}(\mathrm{~cm})$ \\
\hline 612 & 153.3 & 475 & 10 & 500 & 1060 & 134.5 & 850 & 10 \\
570 & 153.5 & 475 & 10 & 500 & 967 & 107.8 & 850 & 10 \\
543 & 153.6 & 437.5 & 10 & 500 & 875 & 81.0 & 662.5 & 10 \\
514 & 153.6 & 437.5 & 10 & 500 & 782 & 54.3 & 662.5 & 10 \\
\hline
\end{tabular}

$$
\frac{\mathrm{d} A}{\mathrm{~d} W}=\left\{\begin{array}{l}
\frac{\mathrm{d} A_{(\mathrm{T}, \mathrm{LSE})}}{\mathrm{d} W_{(\mathrm{T}, \mathrm{LSE})}}=\frac{R^{2}-2 W^{2}}{\sqrt{R^{2}-W^{2}}}+h_{0}-H_{t}-h_{3}+(B-2 W) i=0, \\
\frac{\mathrm{d} A_{(\mathrm{T}, \mathrm{RSE})}}{\mathrm{d} W_{(\mathrm{T}, \mathrm{RSE})}}=\frac{R^{2}-2 W^{2}}{\sqrt{R^{2}-W^{2}}}+h_{0}-H_{t}-h_{3}-(B+2 W) i=0, \\
\frac{\mathrm{d} A_{(\mathrm{TF}, \mathrm{LSE})}}{\mathrm{d} W_{(\mathrm{TF}, \mathrm{LSE})}}=\frac{R^{2}-2 W^{2}}{\sqrt{R^{2}-W^{2}}}-h_{0}-H_{t}-h_{3}+(B-2 W) i=0, \\
\frac{\mathrm{d} A_{(\mathrm{TF}, \mathrm{RSE})}}{\mathrm{d} W_{(\mathrm{TF}, \mathrm{RSE})}}=\frac{R^{2}-2 W^{2}}{\sqrt{R^{2}-W^{2}}}-h_{0}-H_{t}-h_{3}-(B+2 W) i=0 .
\end{array}\right.
$$

Parameter values and superelevations are taken into equation (11), and the guide sign dimension and installation positions $D_{E}$ and $D_{h}$ are obtained as shown in Tables 3 and 4.

\subsection{Analysis of the Guide Sign Dimension under the Same} Superelevation and Different Radii of the Tunnel Vault Circle. In order to investigate the variation regularity of the width, the height, and the area along different radii of the tunnel vault circle under the same superelevation, the diagrams are created as shown in Figures 5-8. Superelevation 2\% is adopted since it is more commonly used for the freeway tunnel alignment design.

As indicated in Figures 5-8, the widths and heights are mutually restrictive with the tunnel clearances. Once the parameters with regard to the inner outline and vertical and horizontal clearances are determined, there is a oneto-one correspondence between the height and the width of the guide sign, and the area is obtained. With the same superelevation, the height, the width, and the area of the guide sign increase with the increase of the radius of the tunnel vault circle. For either two-lane or three- and fourlane freeway tunnels, the height of the guide sign reduces with the increase of its width. The area of the guide sign increases and then reduces with the increase of the width of the guide sign. There is only one set of the width and the height to obtain the maximum area of the guide sign in freeway tunnel.

When the values of all parameters are the same, the maximum values of the widths and the heights of the guide sign are larger under the left superelevation condition than the values under the right superelevation condition. Taking $R=612 \mathrm{~m}$ for the two-lane freeway tunnels as an example, the maximum value of the width is $605.7 \mathrm{~cm}$ under the left superelevation condition, $20.2 \mathrm{~cm}$ wider than the maximum width under the right superelevation condition. The maximum value of the height is $178.5 \mathrm{~cm}$ under the left superelevation condition, $13.2 \mathrm{~cm}$ higher than the maximum height under the right superelevation condition. This regularity has been also seen for the three- or four-lane freeway tunnel. What is more, the bigger radius is, the greater the difference in widths and in heights between the left superelevation condition and the right superelevation condition is. When $R=1060 \mathrm{~m}$, the maximum value of the width for the left superelevation condition is coming up to $37.7 \mathrm{~cm}$ wider than the value for the right superelevation condition. 
TABle 3: Guide sign dimension for two-lane freeway tunnels.

\begin{tabular}{|c|c|c|c|c|c|c|c|c|c|c|}
\hline$R(\mathrm{~m})$ & $h 0(\mathrm{~cm})$ & $h_{3}(\mathrm{~cm})$ & $H_{t}(\mathrm{~cm})$ & $B(\mathrm{~cm})$ & $I$ & $2 W(\mathrm{~cm})$ & $H(\mathrm{~cm})$ & $2 A\left(\mathrm{~cm}^{2}\right)$ & $D_{E}(\mathrm{~cm})$ & $D_{h}(\mathrm{~cm})$ \\
\hline \multirow{7}{*}{612} & \multirow{7}{*}{153.3} & \multirow{7}{*}{10} & \multirow{7}{*}{500} & \multirow{7}{*}{475} & $L S 0.04^{1}$ & 603.1 & 182.8 & 110226 & 173.5 & 493.1 \\
\hline & & & & & LS 0.03 & 604.4 & 180.7 & 109180 & 172.8 & 494.8 \\
\hline & & & & & LS 0.02 & 605.7 & 178.5 & 108137 & 172.1 & 496.6 \\
\hline & & & & & 0 & 608.5 & 174.3 & 106055 & 170.8 & 500.0 \\
\hline & & & & & $R S 0.02^{2}$ & 585.5 & 165.3 & 96818 & 767.8 & 515.4 \\
\hline & & & & & RS 0.03 & 573.9 & 161.0 & 92384 & 762.0 & 522.9 \\
\hline & & & & & $R S 0.04$ & 562.3 & 156.6 & 88071 & 756.1 & 530.2 \\
\hline \multirow{7}{*}{570} & \multirow{7}{*}{153.5} & \multirow{7}{*}{10} & \multirow{7}{*}{500} & \multirow{7}{*}{475} & LS 0.04 & 537.5 & 154.4 & 82999 & 206.3 & 491.7 \\
\hline & & & & & LS 0.03 & 538.2 & 152.2 & 81890 & 205.9 & 493.8 \\
\hline & & & & & LS 0.02 & 538.9 & 149.9 & 80782 & 205.6 & 495.9 \\
\hline & & & & & 0 & 540.3 & 145.4 & 78568 & 204.8 & 500.0 \\
\hline & & & & & $R S 0.02$ & 517.2 & 136.8 & 70748 & 733.6 & 514.7 \\
\hline & & & & & RS 0.03 & 505.4 & 132.6 & 67012 & 727.7 & 521.8 \\
\hline & & & & & RS 0.04 & 493.6 & 128.4 & 63392 & 721.8 & 528.9 \\
\hline \multirow{7}{*}{543} & \multirow{7}{*}{153.6} & \multirow{7}{*}{10} & \multirow{7}{*}{500} & \multirow{7}{*}{437.5} & LS 0.04 & 492.6 & 135.2 & 66587 & 191.2 & 492.4 \\
\hline & & & & & LS 0.03 & 493.2 & 133.1 & 65645 & 190.9 & 494.3 \\
\hline & & & & & LS 0.02 & 493.9 & 131.0 & 64704 & 190.6 & 496.2 \\
\hline & & & & & 0 & 495.2 & 126.9 & 62823 & 189.9 & 500.0 \\
\hline & & & & & RS 0.02 & 472.7 & 119.0 & 56245 & 673.8 & 513.5 \\
\hline & & & & & $R S 0.03$ & 461.3 & 115.1 & 53111 & 668.1 & 520.0 \\
\hline & & & & & RS 0.04 & 449.8 & 111.3 & 50081 & 662.4 & 526.5 \\
\hline \multirow{7}{*}{514} & \multirow{7}{*}{153.6} & \multirow{7}{*}{10} & \multirow{7}{*}{500} & \multirow{7}{*}{437.5} & LS 0.04 & 444.8 & 115.6 & 51418 & 215.1 & 491.4 \\
\hline & & & & & LS 0.03 & 444.8 & 113.4 & 50461 & 215.1 & 493.5 \\
\hline & & & & & LS 0.02 & 444.9 & 111.3 & 49505 & 215.0 & 495.7 \\
\hline & & & & & 0 & 445.1 & 106.9 & 47591 & 214.9 & 500.0 \\
\hline & & & & & RS 0.02 & 422.2 & 99.3 & 41915 & 648.6 & 513.0 \\
\hline & & & & & $R S 0.03$ & 410.5 & 95.6 & 39227 & 642.8 & 519.3 \\
\hline & & & & & RS 0.04 & 398.8 & 91.9 & 36638 & 636.9 & 525.5 \\
\hline
\end{tabular}

${ }^{1} L S$ stands for the left superelevation. ${ }^{2} R S$ stands for the right superelevation.

TABle 4: Guide sign dimension for three- and four-lane freeway tunnels.

\begin{tabular}{|c|c|c|c|c|c|c|c|c|c|c|}
\hline$R(\mathrm{~m})$ & h0 $(\mathrm{cm})$ & $H_{3}(\mathrm{~cm})$ & $H_{t}(\mathrm{~cm})$ & $B(\mathrm{~cm})$ & i & $2 W(\mathrm{~cm})$ & $H(\mathrm{~cm})$ & $2 A\left(\mathrm{~cm}^{2}\right)$ & $D_{E}(\mathrm{~cm})$ & $D_{h}(\mathrm{~cm})$ \\
\hline \multirow{7}{*}{1060} & \multirow{7}{*}{134.5} & \multirow{7}{*}{10} & \multirow{7}{*}{500} & \multirow{7}{*}{850} & $L S 0.04^{1}$ & 1017.9 & 299.0 & 304316 & 341.0 & 486.4 \\
\hline & & & & & LS 0.03 & 1019.7 & 295.0 & 300846 & 340.1 & 489.8 \\
\hline & & & & & LS 0.02 & 1021.6 & 291.1 & 297379 & 339.2 & 493.2 \\
\hline & & & & & 0 & 1025.3 & 283.3 & 290455 & 337.3 & 500.0 \\
\hline & & & & & RS $0.02^{2}$ & 983.9 & 267.6 & 263281 & 1341.9 & 526.8 \\
\hline & & & & & RS 0.03 & 962.9 & 259.9 & 250269 & 1331.5 & 539.9 \\
\hline & & & & & RS 0.04 & 941.8 & 252.3 & 237638 & 1320.9 & 552.8 \\
\hline \multirow{7}{*}{967} & \multirow{7}{*}{107.8} & \multirow{7}{*}{10} & \multirow{7}{*}{500} & \multirow{7}{*}{850} & LS 0.04 & 899.5 & 254.3 & 228703 & 400.3 & 484.0 \\
\hline & & & & & LS 0.03 & 900.0 & 250.1 & 225103 & 400.0 & 488.0 \\
\hline & & & & & LS 0.02 & 900.6 & 246.0 & 221503 & 399.7 & 492.0 \\
\hline & & & & & 0 & 901.8 & 237.6 & 214304 & 399.1 & 500.0 \\
\hline & & & & & RS 0.02 & 860.8 & 222.5 & 191552 & 1280.4 & 525.6 \\
\hline & & & & & RS 0.03 & 840.0 & 215.1 & 180707 & 1270.0 & 538.1 \\
\hline & & & & & RS 0.04 & 819.0 & 207.8 & 170215 & 1259.5 & 550.4 \\
\hline \multirow{7}{*}{875} & \multirow{7}{*}{81.0} & \multirow{7}{*}{10} & \multirow{7}{*}{500} & \multirow{7}{*}{662.5} & LS 0.04 & 772.2 & 205.3 & 158505 & 276.4 & 488.9 \\
\hline & & & & & LS 0.03 & 773.5 & 202.1 & 156371 & 275.8 & 491.7 \\
\hline & & & & & LS 0.02 & 774.8 & 199.1 & 154239 & 275.1 & 494.5 \\
\hline & & & & & 0 & 777.6 & 192.9 & 149979 & 273.7 & 500.0 \\
\hline & & & & & RS 0.02 & 741.6 & 180.9 & 134142 & 1033.3 & 520.7 \\
\hline & & & & & RS 0.03 & 723.4 & 175.0 & 126607 & 1024.2 & 530.7 \\
\hline & & & & & RS 0.04 & 705.0 & 169.3 & 119325 & 1015.0 & 540.6 \\
\hline \multirow{7}{*}{782} & \multirow{7}{*}{54.3} & \multirow{7}{*}{10} & \multirow{7}{*}{500} & \multirow{7}{*}{662.5} & LS 0.04 & 648.7 & 160.8 & 104303 & 338.2 & 486.5 \\
\hline & & & & & LS 0.03 & 648.5 & 157.5 & 102110 & 338.3 & 489.9 \\
\hline & & & & & LS 0.02 & 648.3 & 154.1 & 99916 & 338.4 & 493.2 \\
\hline & & & & & 0 & 647.9 & 147.4 & 95529 & 338.6 & 500.0 \\
\hline & & & & & $R S 0.02$ & 611.6 & 136.1 & 83216 & 968.3 & 519.4 \\
\hline & & & & & $R S 0.03$ & 593.2 & 130.5 & 77410 & 959.1 & 528.8 \\
\hline & & & & & RS 0.04 & 574.7 & 125.0 & 71836 & 949.8 & 538.0 \\
\hline
\end{tabular}

${ }^{1} L S$ stands for the left superelevation. ${ }^{2} R S$ stands for the right superelevation. 


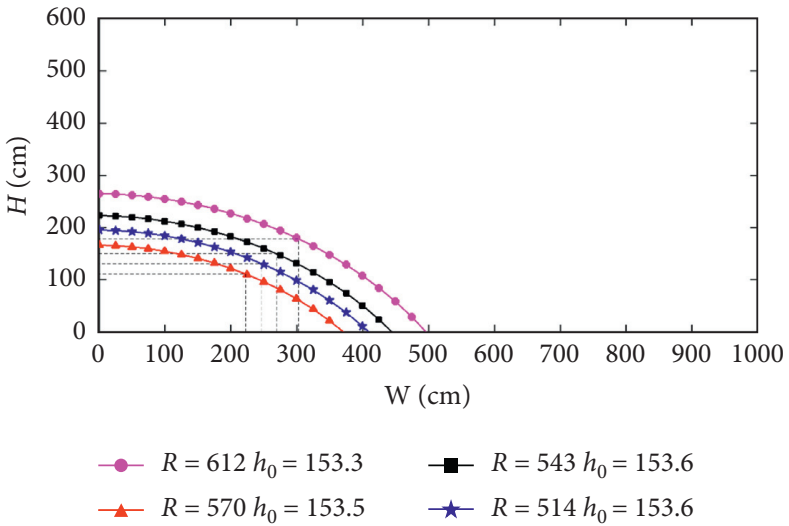

(a)
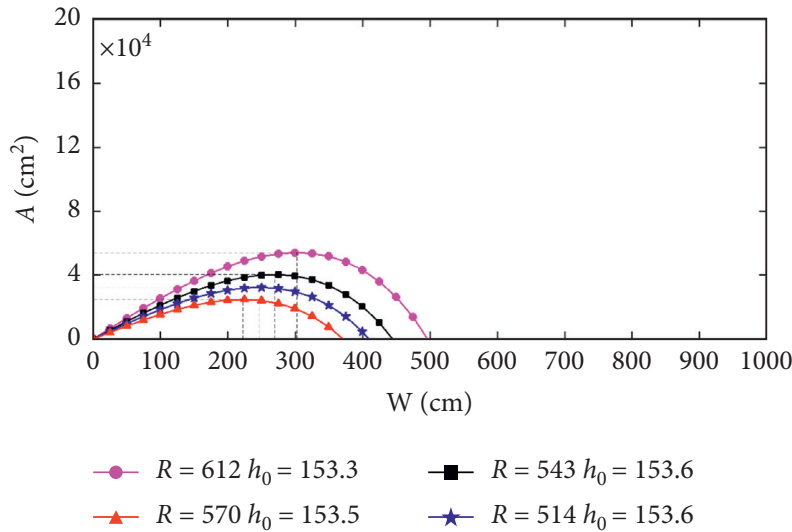

(b)

FIGURE 5: The relationship diagrams between the height and the widths with the area of the guide sign, left superelevation $2 \%$ under two-lane freeway tunnel. (a) Height-Width. (b) Area-Width.

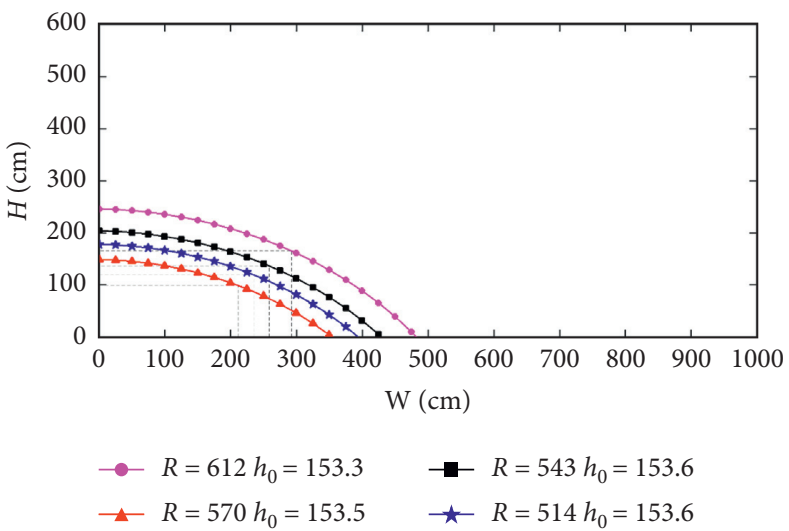

(a)

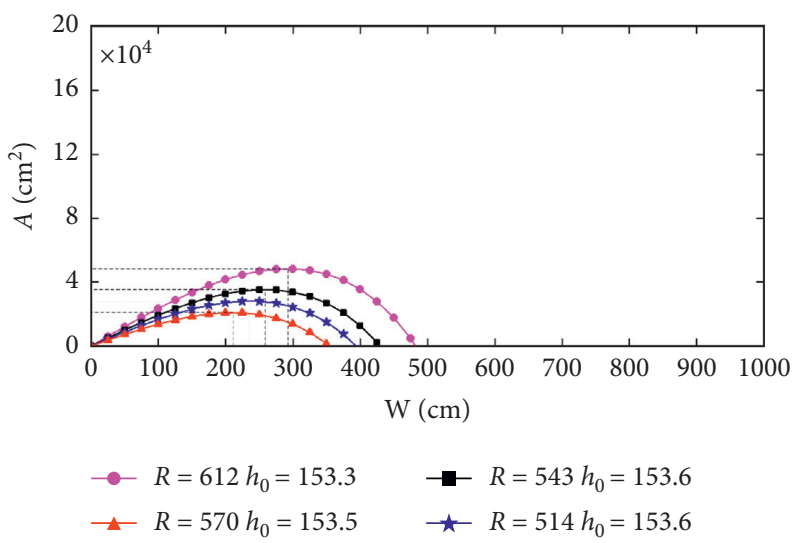

(b)

FIgURE 6: The relationship diagrams between the height and the widths with the area of the guide sign, right superelevation $2 \%$ under twolane freeway tunnel. (a) Height-Width. (b) Area-Width.

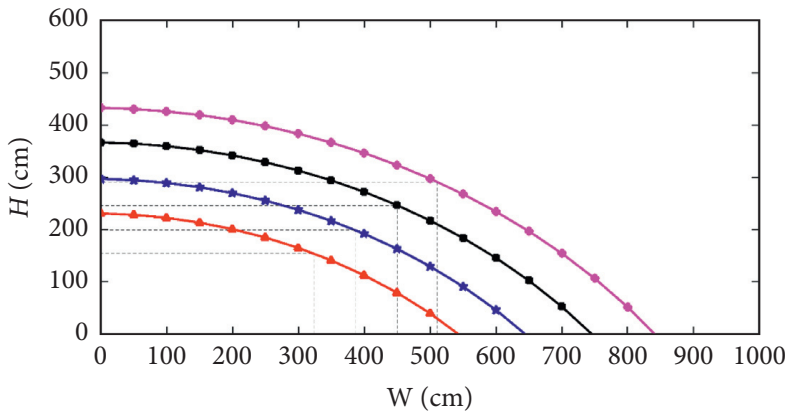

$\longrightarrow R=1060 h_{0}=134.5 \quad \rightarrow R=875 h_{0}=81.0$
$\neg R=967 h_{0}=107.8 \quad \rightarrow R=782 h_{0}=54.3$

(a)

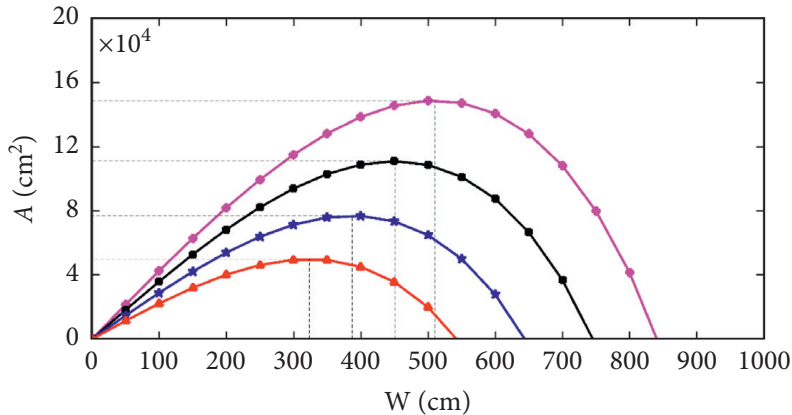

$$
\begin{array}{ll}
\rightarrow R=1060 h_{0}=134.5 & \rightarrow R=875 h_{0}=81.0 \\
\triangle R & =967 h_{0}=107.8 \quad \rightarrow R=782 h_{0}=54.3
\end{array}
$$

(b)

FIGURE 7: The relationship diagrams between the height and the widths with the area of the guide sign, left superelevation $2 \%$ under threeand four-lane freeway tunnel. (a) Height-Width. (b) Area-Width. 


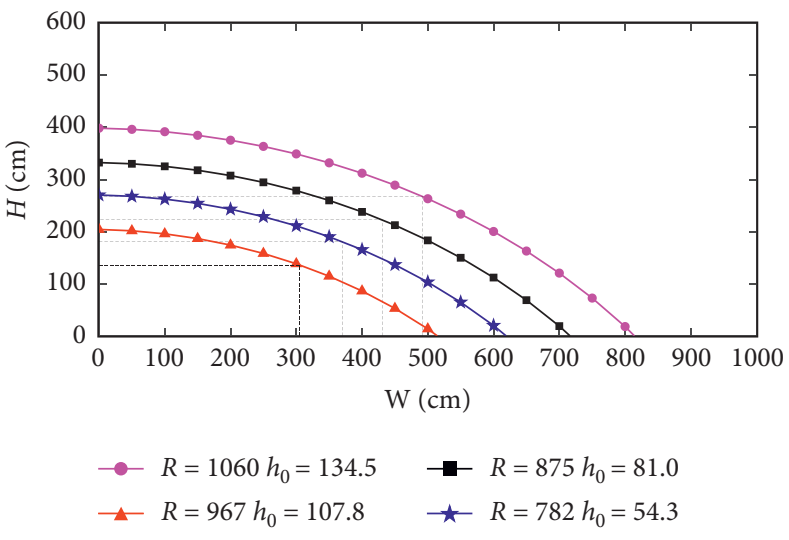

(a)

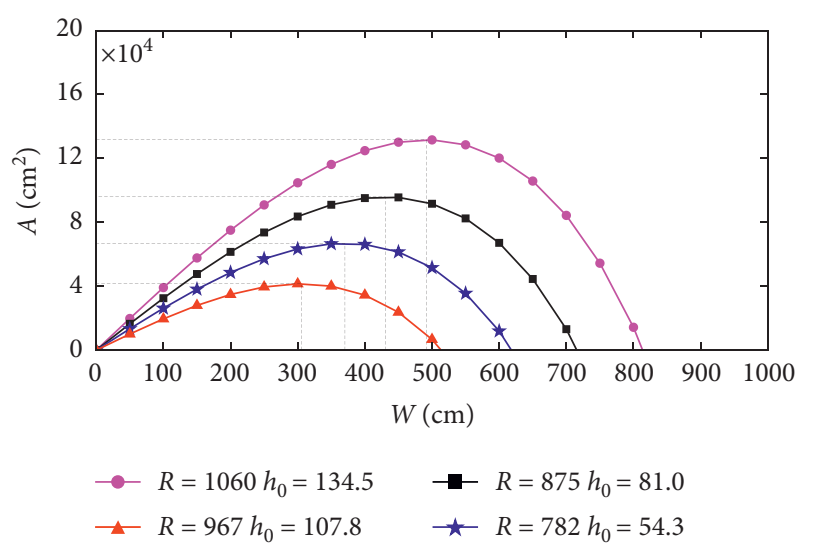

(b)

FIGURE 8: The relationship diagrams between the height and the widths with the area of the guide sign, right superelevation $2 \%$ under threeand four-lane freeway tunnel. (a) Height-Width. (b) Area-Width.

\subsection{Analysis of the Guide Sign Dimension under the Different} Superelevation and Same Radii of the Tunnel Vault Circle. In order to investigate the influence of the different superelevation on the dimension size of the guide sign, the superelevation grades $0 \%, 2 \%$, and $4 \%$ were selected. The diagrams of the variation regularity of the width, the height, and the area of the guide sign along the $R=612 \mathrm{~m}$ for the two-lane and $R=1062 \mathrm{~m}$ for the three- or four-lane freeway tunnel were created as shown in Figures 9 and 10.

As indicated in Figures 9 and 10, the integral changing trend maintains unchanged. For either left superelevation or right superelevation, the height of the guide sign reduces with the increase of its width, and the area of the guide sign increases and then reduces with the increase of the width of the guide sign.

When the superelevation grades increase, the changing trend of the dimension of the guide sign under left superelevation condition is different from the changing trend under right superelevation. Under the left superelevation condition, the height and the area of the guide sign increase with the increase of the superelevation. However, under the right superelevation condition, the height and the area of the guide sign decrease with the increase of the superelevation.

What is more, increasing with the superelevation grades along the freeway tunnel section with the same radii, the changing extent of the guide sign dimension under the right superelevation condition is greater than the left superelevation condition. Taking $R=1060 \mathrm{~m}$ for the three- and fourlane freeway tunnels as an example, when the grade of the left superelevation is increased from $2 \%$ to $4 \%$, the height of the guide sign increased, $7.9 \mathrm{~cm}$; when the grade of the right superelevation is increased from $2 \%$ to $4 \%$, the height of the guide sign decreased, $15.3 \mathrm{~cm}$. The change of the height on the right condition is almost twice as that of the height on the left condition.

\section{Discussion}

Combining the research results with analysis in the literature review, at the same superelevation, for either two-lane or three- and four-lane tunnel, the dimension of guide sign under left superelevation is larger than that under right superelevation. This phenomenon results from the datum mark. The datum mark is always at the left side along the direction of traffic flow. As a result, the design of left superelevation expands the installation space. When the cross section is around the datum mark to form the right superelevation, the installation space for guide sign would be reduced.

For the same reason of the datum mark, at the same radius of the tunnel vault, there will be different change trend of height with width under different superelevation grade between left superelevation and right superelevation. The left superelevation is around the datum mark to form the left superelevation, and the installation space for guide sign would be enlarged. The larger the left superelevation grade, the larger the height of guide sign.

At the mention of guide sign dimension, the size and the style of Chinese characters and signs, the interline, and edge spacing were mostly considered. It is necessary to consider these elements. However, it has to take into account firstly whether there is enough space to accommodate the big size of the guide sign in the freeway tunnel. Some researchers did not consider the vertical and horizontal clearances of highway tunnel adequately and recommended the traffic signs size for two-lane and three-lane tunnels in respect of design speeds, character heights, character, and line spacing. The dimensions of guide signs for the one-way two-lane tunnel are $660 \mathrm{~cm} \times 125 \mathrm{~cm}$ (all same as width $\times$ height) and $730 \mathrm{~cm} \times 100 \mathrm{~cm}$ with design speeds of $80 \mathrm{~km} / \mathrm{h}$ and $60 \mathrm{~km} /$ $h$, respectively [4]. The dimensions of guide signs for the one-way three-lane tunnel are $1010 \mathrm{~cm} \times 125 \mathrm{~cm}$ and $1070 \mathrm{~cm} \times 100 \mathrm{~cm}$ with design speeds of $80 \mathrm{~km} / \mathrm{h}$ and $60 \mathrm{~km} / \mathrm{h}$, respectively [4]. However, the widths of the shoulder, the curb, and the sidewalk of the left side could be different from the right side even though being at the same design speed, which would result in different values of the radius of the tunnel vault circle, and then further influence the effective setting space for guide sign. Under the same superelevation value $i=2 \%$ in this paper, the maximum 


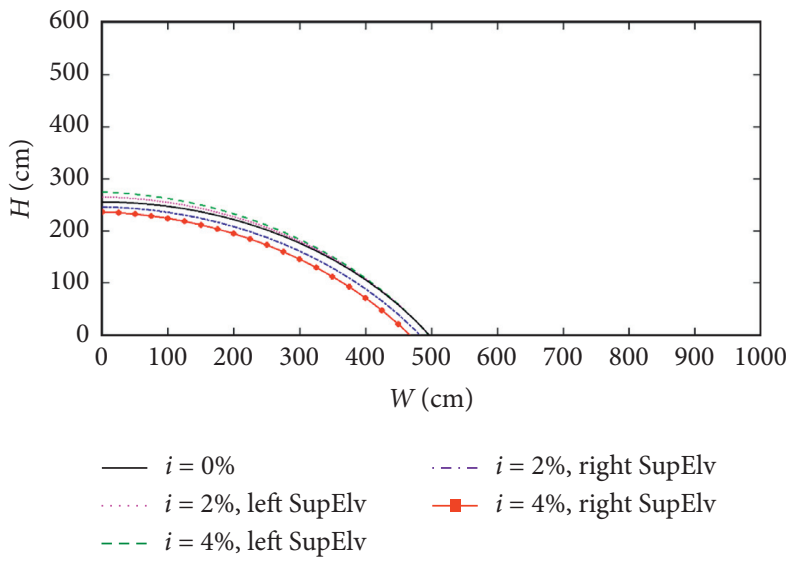

(a)

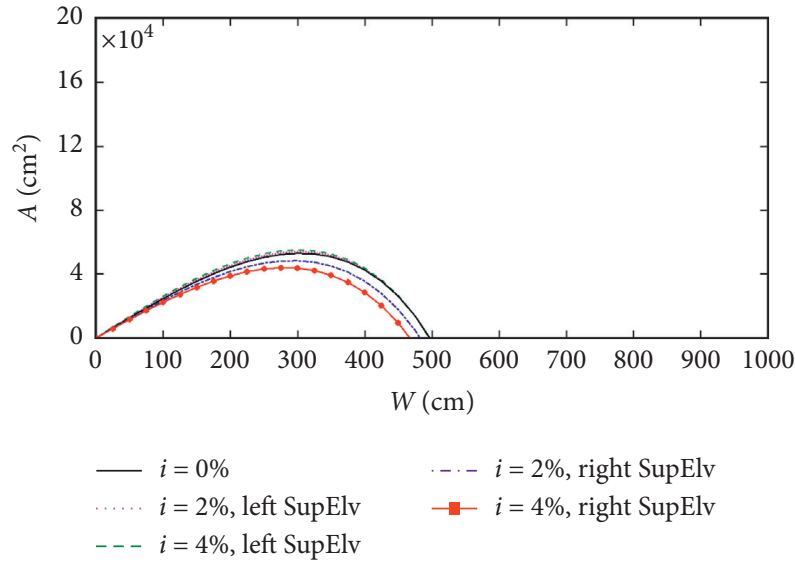

(b)

Figure 9: The relationship diagrams between the height and the widths with the area of the guide sign, $R=612 \mathrm{~m}$ in two-lane freeway tunnel. (a) Height-Width. (b) Area-Width.

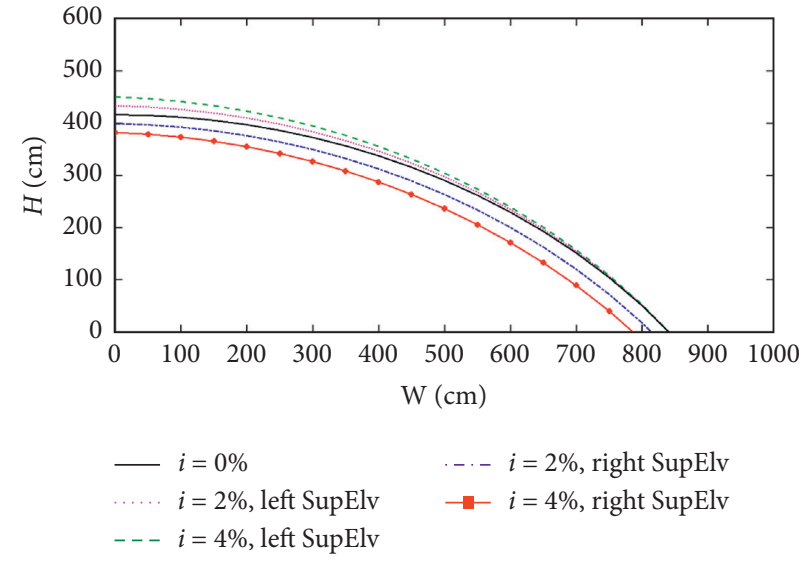

(a)

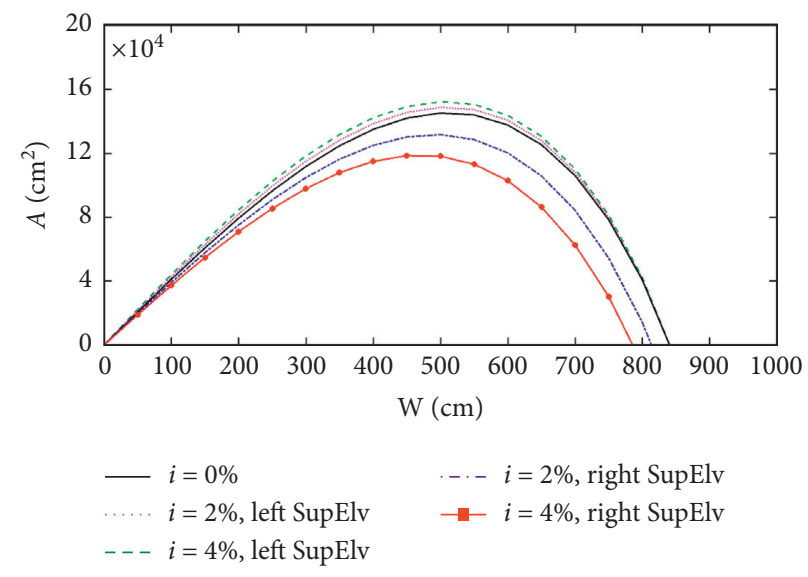

(b)

Figure 10: The relationship diagrams between the height and the width with the area of the guide sign, $R=1060 \mathrm{~m}$ in three- or four-lane freeway tunnel. (a) Height-Width. (b) Area-Width.

dimension of guide sign is $605 \mathrm{~cm} \times 178 \mathrm{~cm}$ for the one-way two-lane tunnel, and $1021 \mathrm{~cm} \times 291 \mathrm{~cm}$ for the one-way three-lane tunnel. The widths of guide sign in tunnel in this paper are all less than those in the previous study. This result indicated that the geometric elements associated with inner outline should be considered adequately, and the dimension of guide sign in tunnel should not be determined just by words, characters, or interline and edge spacing.

Even though the design speeds would not influence the horizontal and vertical clearances in the tunnel, there is a certain correlation between the design speeds with the radius of tunnel vault from the practical construction experiences. For the two-lane freeway tunnel, the results of the guide sign dimension under $R=612 \mathrm{~m}, R=570 \mathrm{~m}$ or $543 \mathrm{~m}$, and $R=514 \mathrm{~m}$ would be applied in the tunnel at the design speeds $100 \mathrm{~km} / \mathrm{h}, 80 \mathrm{~km} / \mathrm{h}$, and $60 \mathrm{~km} / \mathrm{h}$, respectively. For the three- and four-lane freeway tunnels, the results of the guide sign dimension under $R=1060 \mathrm{~m}$ or $967 \mathrm{~m}, R=967 \mathrm{~m}$ or $875 \mathrm{~m}$, and $R=875 \mathrm{~m}$ or $782 \mathrm{~m}$ would be applied in the tunnel at the design speeds $120 \mathrm{~km} / \mathrm{h}, 100 \mathrm{~km} / \mathrm{h}$, and $80 \mathrm{~km} / \mathrm{h}$, respectively.

For the characteristics and the maximum dimension of guide sign in tunnels elaborated above, the design traffic sign in the tunnel should be considered in the preliminary design stage of tunnel. If there is interchange in the tunnel sections or the distance between the interchange exit ramps and the tunnel exit is short, guide signs in tunnel should be provided for drivers. The alignment in the relative section in the tunnel, left superelevation or right superelevation, left curve or right curve, should be designed in combination with the required maximum dimension of the guide sign. This is a kind of advanced design method compared with current design methods. 


\section{Conclusions}

The design parameters of tunnel inner outlines, the vertical and horizontal clearances and the superelevations, were taken into account to establish the model of the dimension of guide signs in tunnel. Since the position of the tunnel vault center for two-lane tunnel is different from that for three- or four-lane tunnel, the dimensions of guide sign in tunnel were calculated in two classifications. The calculation models and the relative results were proposed, and the calculation models are applicable for other design parameters of tunnels.

Generally, the height of the guide sign reduces with the increase of the widths of it. The area of the guide sign increases and then reduces with the increase of the width of the guide sign. With the same superelevation, the height, the width, and the area of the guide sign increase with the increase of the radius of the tunnel vault circle. Under the same radius of the tunnel vault circle, the changing trend of heights with widths of the guide sign under the left superelevation is different from the right superelevation situation. The dimension of the guide sign changes slightly with the increase of left superelevation grades and changes obviously with the increase of right superelevation grades. The research results could provide guidance for the design methods of guide sign in tunnels and are beneficial for the comprehensive design of other facilities, such as lighting and the fan system.

\section{Data Availability}

The parameter values of two-lane one-way tunnel in Table 2 data used to support the findings of this study are from the Code for Design of Road Tunnel and Technical Standard of Highway Engineering, which have been cited. The parameters values of three- and four-lane one-way tunnels in Table 2 data used to support the findings of this study are from specific tunnels that have been in operation, which are available from the corresponding author upon request. The data in Tables 3 and 4 are calculated by (11) using parameter values in Table 2. Therefore, all of the data used to support the findings of this study are included within this article.

\section{Conflicts of Interest}

The authors declare that there are no conflicts of interest regarding the publication of this paper.

\section{Acknowledgments}

This research was funded by National Key R\&D Program of China (Grant nos. 2018YFB1600302 and 2018YFB1600300) and supported by National Natural Science Foundation of China (Grant no. 61531005) and Transport Science and Technology Program of Shaanxi (Grant no. 2015-11K).

\section{References}

[1] Ministry of Transport of the People's Republic of China, Statistical Bulletin on Transportation Industry Development, Ministry of Transport of the People's Republic of China, Beijing, China, 2019.

[2] B. Yan, J. Zhou, and L. Wang, "Effectiveness of traffic sign setting in adjacent tunnel exit," Procedia-Social and Behavioral Sciences, vol. 96, pp. 5-11, 2013.

[3] Y. Pu, F. Chen, X. Pan, J. Liang, H. Peng, and Y. Wu, "The legibility of LED traffic guide signs in urban tunnels," in Proceedings of 2017 4th International Conference on Transportation Information and Safety (ICTIS), pp. 1111-1116, Banff, Canada, August 2017.

[4] Z. Wu and A. Dong, "Setting of traffic sign in tunnel based on the visual continuity," Journal of Railway Science \& Engineering, vol. 13, pp. 369-374, 2016.

[5] T. Deng, W. Wei, Z. Guan, and Y. Miao, "Complex variable function solution and its application for road tunnel excavation," China Journal of Highway and Transport, vol. 28, pp. 90-97, 2015.

[6] S. Li, Study on the Optimization of Design Parameters and Construction Technology of Underground Interchange Tunnel, Beijing Jiaotong University, Beijing, China, 2011.

[7] S. Luo, Parametric Design Study of Highway Tunnel Based on ObjectARX, Southwest Jiaotong University, Chengdu, China, 2007.

[8] Editorial Department of China journal of highway and Transport, "Review on China's tunnel engineering research: 2015," China Journal of Highway and Transport, vol. 28, no. 5, pp. 1-65, 2015.

[9] X. Yu and L. Peng, "Optimum design model of inner outline of double multi-arch tunnel and its application," Central South Highway Engineering, vol. 31, pp. 79-82, 2006.

[10] H. Ding, "Statistical analysis for key indicators of contour in single-hole and 4-lane tunnels and enlightenment," Technology of Highway and Transport, vol. 6, pp. 89-91, 2012.

[11] O. Dollmann, U. Horny, and A. Schulter, "Risk-based design for large tunnel cross sections in soft ground," Underground. The Way to the Future, CRC Press, London, UK, 2013.

[12] K. Haruyama, S. Teramoto, H. Harada, and M. Mori, "Construction of urban expressway tunnel with special large cross section by NATM-metropolitan inter-city highway (ken-O-do) ome tunnel," 2001.

[13] K. Haruyama, S. Teramoto, and K. Taira, "Construction of large cross-section double-tier metropolitan inter-city highway (kenO-do) ome tunnel by NATM," Tunnelling and Underground Space Technology, vol. 20, no. 2, pp. 111-119, 2005.

[14] L. Huang and Q. Qian, "Study on excavation schemes for the redevelopment construction of highway tunnels with large sections," Modern Tunnelling Technology, vol. 53, pp. 145-153, 2016.

[15] Chongqing Communication Technology Research \& Design Institute Co., Ltd., Specifications for Design of Highway Tunnels, Civil Engineering, China Communications Publishing \& Media Management Co., Ltd., Beijing, China, 2019.

[16] Highway Administration of Ministry of Transport of the People's Republic of China, CCCC First Highway Consultants Co., Ltd., Technical Standard of Highway Engineering, China Communications Publishing \& Media Management Co., Ltd., Beijing, China, 2014. 